\title{
Application of the Modified Vlasov Model to the free vibration analysis of thick plates resting on elastic foundations
}

\author{
Korhan Ozgan* and Ayse T. Daloglu \\ Department of Civil Engineering, Karadeniz Technical University, 61080 Trabzon, Turkey
}

Received 10 July 2007

Revised 20 January 2008

\begin{abstract}
The Modified Vlasov Model is applied to the free vibration analysis of thick plates resting on elastic foundations. The effects of the subsoil depth, plate dimensions and their ratio, the value of the vertical deformation parameter within the subsoil on the frequency parameters of plates on elastic foundations are investigated. A four-noded, twelve degrees of freedom quadrilateral finite element (PBQ4) is used for plate bending analysis based on Mindlin plate theory which is effectively applied to the analysis of thin and thick plates when selective reduced integration technique is used. The first ten natural frequency parameters are presented in tabular and graphical forms to show the effects of the parameters considered in the study. It is concluded that the effect of the subsoil depth on the frequency parameters of the plates on elastic foundation is generally larger than that of the other parameters considered in the study.
\end{abstract}

Keywords: Finite element method, thick plate theory, elastic foundation, Vlasov Model, free vibration

\section{Notations}

$\begin{array}{ll}a: & \text { half length of an element in } x \text { direction } \\ b: & \text { half length of an element in } y \text { direction } \\ D: & \text { the flexural rigidity of the plate } \\ E_{s}: & \text { modulus of elasticity of subsoil } \\ \{F\}: & \text { applied equivalent load vector of the system } \\ h: & \text { thickness of the plate } \\ H: & \text { depth of the subsoil } \\ k: & \text { modulus of subgrade reaction } \\ {\left[k_{p}\right]:} & \text { element stiffness matrix of the plate } \\ {\left[k_{w}\right]:} & \text { vertical deflection element stiffness matrix of the foundation } \\ {\left[k_{2 t}\right]:} & \text { shear deformation element stiffness matrix of the foundation } \\ {[K]:} & \text { stiffness matrix of the plate-soil system } \\ l_{x}: & \text { lenght of the plate in } \mathrm{x} \text { direction } \\ l_{y}: & \text { lenght of the plate in y direction } \\ {[M]:} & \text { mass matrix of the plate-soil system } \\ {\left[N_{i}\right]:} & \text { shape functions } \\ u, v \text { and } w: & \text { displacement of the plate in } x, y \text { and } z \text { direction } \\ \bar{u}, \bar{v} \text { and } \bar{w}: & \text { displacement of the soil in } x, y \text { and } z \text { direction }\end{array}$

\footnotetext{
${ }^{*}$ Corresponding author: Korhan Ozgan, Ph.D., Karadeniz Technical University, Faculty of Engineering, Civil Engineering Department, 61080 Trabzon, Turkey. Tel.: +90 462377 2662; Fax: +90 462377 2606; E-mail: kozgan@ktu.edu.tr or korhanozgan@yahoo.com.
} 


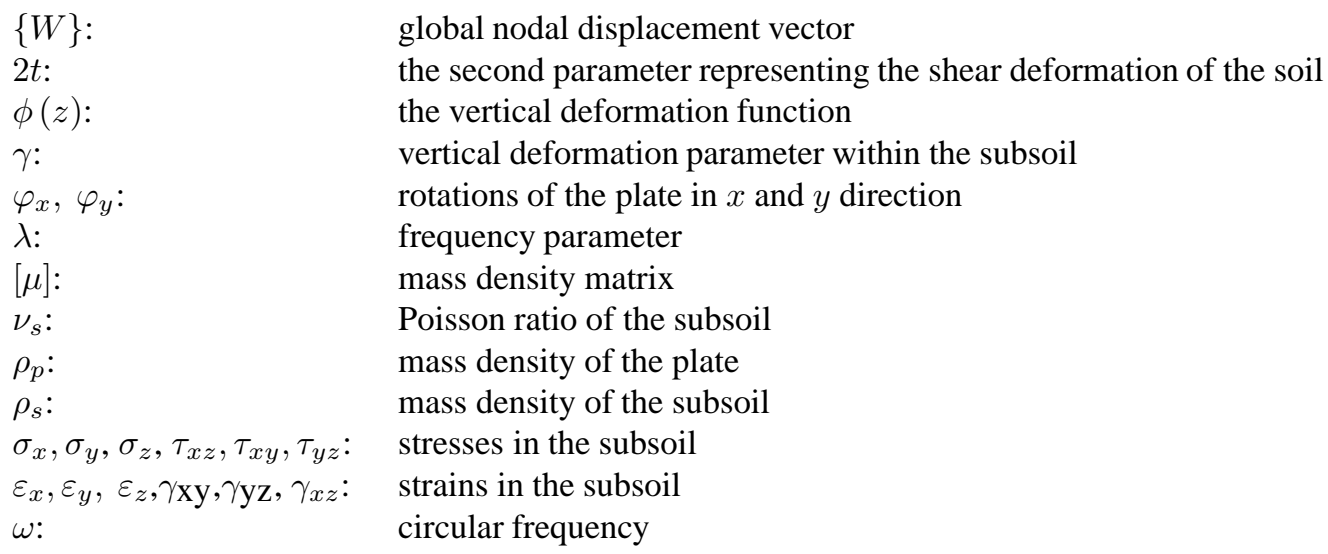

\section{Introduction}

The dynamic behaviour of the plates on elastic foundations has been the subject of intensive studies for many years due to their great importance in many engineering applications such as mat and raft foundations, highways and airfield pavements. Free vibration analysis is an important part of engineering investigations because the knowledge of natural frequencies of vibration and associated mode shapes are guide for researcher in the dynamic analysis. Most of the studies done in this area are based on the classical thin plate theory ignoring the effect of shear deformation through the plate thickness. And consequently natural frequencies calculated by using classical thin plate theory become different from what have been expected. On the other hand, it is really important to use a realistic subsoil model to analyze the soil structural system. The simplest and widely used one is Winkler Model, where the vertical resistance of soil is represented by vertical distributed elastic springs and each spring is independent of the others. The main shortcoming of Winkler Model is discontinuity of the elastic springs and necessity of determining coefficient of the elastic springs. To overcome this problem, some researches developed two parameter models connecting the top ends of vertical springs by a fictitious membrane or shear layer or elastic plate. The drawback of the two parameter models lies in the difficulty of establishing the soil parameters, $k$ and $2 t$. The investigators modified the two parameter models by proposing a computational technique to calculate these two soil parameters iteratively. They introduced another parameter, $\gamma$, to characterize the vertical deformation profile within the subsoil, and called the model as Modified Vlasov Model. The advantages of this model is the elemination of the necessity to determine the values of soil parameters, $k$ and $2 t$, arbitrarily because these values can be computed as a function of the vertical deformation parameter, $\gamma$. The model is also called as "three parameter model" by some other researchers [1].

Omurtag et al. [2] studied the free vibration analysis of Kirchhoff plates resting on elastic foundation using Gateaux differential. Omurtag and Kadioglu [3] investigated the free vibration analysis of orthotropic Kirchhoff plates resting on elastic foundation. They used Winkler and Pasternak type elastic foundation models. Ayvaz et al. [4] applied the Modified Vlasov Model to earthquake analysis of plates resting on elastic foundation using classical thin plate theory, and investigated the effects of the plate dimensions and subsoil depth on the dynamic out-of-plane responses of plates on elastic foundation. Daloğlu et al. [5] applied the consistent Vlasov Model to dynamic analysis of plates resting on elastic foundations subjected to external loads using classical plate theory. Matsunaga [6] solved the problem of vibration and stability of plates on elastic foundation including the effect of shear deformation. Shen et al. [7] examined the free and forced vibration analysis for a Reissner-Mindlin plate with four free edges resting on Pasternak type elastic foundation. They investigated effects of the parameters such as foundation stiffness, transverse shear deformation and plate aspect ratio on dynamic response of Reissner-Mindlin plates. Xiang [8] considered the problem of vibration of rectangular Mindlin plates resting on non- homogenous elastic foundation. Malekzadeh and Karami [9] used differential quadrature method for vibration of thick plates on elastic foundation and considered continuously varying thickness of plate. Leung and Zhu [10] presented an analytical trapezoidal hierarchical element for the transverse vibration of Mindlin plates resting on two parameter foundation using Legendre orthogonal polynomials to avoid shear locking problem. Zhou et al. [11] analyzed 


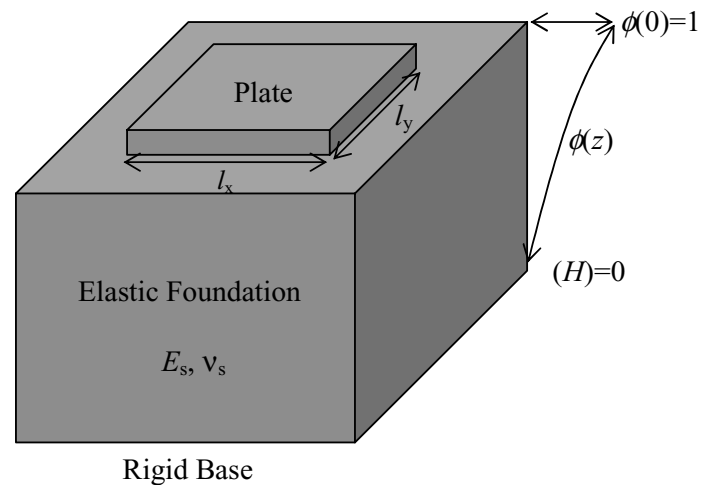

Fig. 1. A plate on elastic foundation.

the three dimensional vibration problems of thick circular plates resting on elastic foundation and investigated the effects of various thickness-radius ratios, foundation stiffness parameters and boundary conditions on the dynamic behaviour of the thick circular plates on elastic foundation.

The purpose of this paper is to apply both of the Modified Vlasov Model and Mindlin plate theory to the free vibration analysis of the plates on elastic foundations by taking the effect of shear deformation through the plate thickness into account. A computer program is coded for the purpose, and the stiffness and mass matrices of the plate-subsoil system are obtained using finite element method. Then, MATLAB for Windows 5.3 is used to obtain the solution of the generalized eigenvalue problem including these two matrices. Using computer program codded, the effects of various parameters such as subsoil depth, plate dimensions, their ratio and the value of the vertical deformation parameter within the soil on the frequency parameters of plates on elastic foundation are analyzed.

\section{Modified Vlasov Model}

The subsoil considered has a finite depth with a rigid boundary at the bottom (Fig. 1). The total potential energy in the soil-structure system for the unloaded case may be written as

$$
\begin{aligned}
\prod= & \frac{1}{2} \int_{\Omega}\left(\frac{\partial^{2} w}{\partial x^{2}}, \frac{\partial^{2} w}{\partial y^{2}}, 2 \frac{\partial^{2} w}{\partial x \partial y}\right)[D]\left(\frac{\partial^{2} w}{\partial x^{2}}, \frac{\partial^{2} w}{\partial y^{2}}, 2 \frac{\partial^{2} w}{\partial x \partial y}\right)^{T} d x d y \\
& +\frac{1}{2} \int_{0}^{H} \int_{-\infty}^{+\infty} \int_{-\infty}^{+\infty}\left(\sigma_{x} \varepsilon_{x}+\sigma_{y} \varepsilon_{y}+\sigma_{z} \varepsilon_{z}+\tau_{x y} \gamma_{x y}+\tau_{y z} \gamma_{y z}+\tau_{x z} \gamma_{x z}\right) d x d y d z
\end{aligned}
$$

where $\sigma_{x}, \sigma_{y}, \sigma_{z}, \tau_{x z}, \tau_{x y}, \tau_{y z}, \varepsilon_{x}, \varepsilon_{y}, \varepsilon_{z}, \gamma_{x y}, \gamma_{y z}$ and $\gamma_{x z}$ are the stresses and corresponding strains in the subsoil; $w,[D], H$ are displacement of the plate in $z$ direction, the flexural rigidity of the plate and depth of the subsoil respectively. $\Omega$ is domain of the plate. By using constitutive relations and strain-displacement equations of elasticity, the stresses at any point in the foundation can be expressed as

$$
\left\{\begin{array}{c}
\sigma_{x} \\
\sigma_{y} \\
\sigma_{z} \\
\tau_{x y} \\
\tau_{x z} \\
\tau_{y z}
\end{array}\right\}=\bar{E}\left[\begin{array}{cccccc}
1 & \frac{\nu_{s}}{1-\nu_{s}} & \frac{\nu_{s}}{1-\nu_{s}} & 0 & 0 & 0 \\
\frac{\nu_{s}}{1-\nu_{s}} & 1 & \frac{\nu_{s}}{1-\nu_{s}} & 0 & 0 & 0 \\
\frac{\nu_{s}}{1-\nu_{s}} & \frac{\nu_{s}}{1-\nu_{s}} & 1 & 0 & 0 & 0 \\
0 & 0 & 0 & \frac{1-2 \nu_{s}}{2\left(1-\nu_{s}\right)} & 0 & 0 \\
0 & 0 & 0 & 0 & \frac{1-2 \nu_{s}}{2\left(1-\nu_{s}\right)} & 0 \\
0 & 0 & 0 & 0 & 0 & \frac{1-2 \nu_{s}}{2\left(1-\nu_{s}\right)}
\end{array}\right]\left\{\begin{array}{c}
\varepsilon_{x} \\
\varepsilon_{y} \\
\varepsilon_{z} \\
\gamma_{x y} \\
\gamma_{x z} \\
\gamma_{y z}
\end{array}\right\}
$$


where $\bar{E}=\frac{E_{s}\left(1-\nu_{s}\right)}{\left(1+\nu_{s}\right)\left(1-2 \nu_{s}\right)}, E_{s}$ is modulus of elasticity, and $\nu_{s}$ is the Poisson ratio of the subsoil. The displacement of the soil in $x, y$ and $z$ direction can be defined as $\bar{u}, \bar{v}$ and $\bar{w}$ respectively. If the assumptions of

$$
\begin{aligned}
& \bar{u}(x, y, z)=0 \\
& \bar{v}(x, y, z)=0
\end{aligned}
$$

and

$$
\bar{w}(x, y, z)=w(x, y) \phi(z)
$$

are made and if Eqs (2)-(5) are substituted into Eq. (1), the following equation can be obtained.

$$
\begin{aligned}
\prod= & \frac{1}{2} \int_{\Omega}\left(\frac{\partial^{2} w}{\partial x^{2}}, \frac{\partial^{2} w}{\partial y^{2}}, 2 \frac{\partial^{2} w}{\partial x \partial y}\right)[D]\left(\frac{\partial^{2} w}{\partial x^{2}}, \frac{\partial^{2} w}{\partial y^{2}}, 2 \frac{\partial^{2} w}{\partial x \partial y}\right)^{T} d x d y \\
& +\frac{1}{2} \int_{-\infty}^{+\infty} \int_{-\infty}^{+\infty}\left\{k w^{2}+2 t(\nabla w)^{2}\right\} d x d y-\int_{\Omega} q w d x d y
\end{aligned}
$$

The soil parameters $k$ and $2 t$ in above expression are the constants resulting from the integration in the interval $0 \leqslant z \leqslant H$ may be defined as

$$
\begin{aligned}
& k=\int_{0}^{H} \frac{E_{s}\left(1-\nu_{s}\right)}{\left(1+\nu_{s}\right)\left(1-2 \nu_{s}\right)}\left(\frac{\partial \phi}{\partial z}\right)^{2} d z \\
& 2 t=\int_{0}^{H} \frac{E_{s}}{2\left(1+\nu_{s}\right)} \phi^{2} d z
\end{aligned}
$$

in which $\phi(z)$ is the mode shape that gives the variation of the deflection in the $z$ direction such that $\phi(0)=$ 1 and $\phi(H)=0$.

Using the variational principle and minimizing the total potential energy of Eq. (6) by taking variations in $w$ and yields

$$
\delta \Pi=\int_{\Omega}\left(D \nabla^{4} w-2 t \nabla^{2} w+k w-q\right) \delta w d x d y+\int_{0}^{H}\left(-m \frac{\partial^{2} \phi}{\partial z^{2}}+n \phi\right) \delta \phi d z+
$$

boundary conditions $=0$,

where $m=\int_{-\infty}^{+\infty} \int_{-\infty}^{+\infty} \bar{E} w^{2} d x d y$, and $n=\int_{-\infty}^{+\infty} \int_{-\infty}^{+\infty} G(\nabla w) d x d y$ in which $G=\frac{E_{s}}{2\left(1+\nu_{s}\right)}$. Since the variations $\delta w$ and $\delta \phi$ are not equal to zero, the terms in the parentheses and the boundary conditions must be equal to zero.

Therefore the main field equation of the plate on an elastic foundation can be obtained as

$$
D \nabla^{4} w-2 t \nabla^{2} w+k w=q
$$

where $\nabla^{2}$ is the Laplace and $\nabla^{4}$ is the biharmonic operators. The second expression within the parentheses in Eq. (8) is the field equation for the deformation pattern of the soil in the vertical direction with the boundary conditions $\phi(0)=1$ and $\phi(H)=0$ as shown in Fig. 1 . The solution of the differential equation

$$
-m \frac{\partial^{2} \phi}{\partial z^{2}}+n \phi=0
$$

with the given boundary conditions yields

$$
\phi(z)=\frac{\sinh \gamma\left(1-\frac{z}{H}\right)}{\sinh \gamma}
$$

where $\gamma$ represents the vertical deformation parameter within the subsoil and is calculated using the equation shown below. 


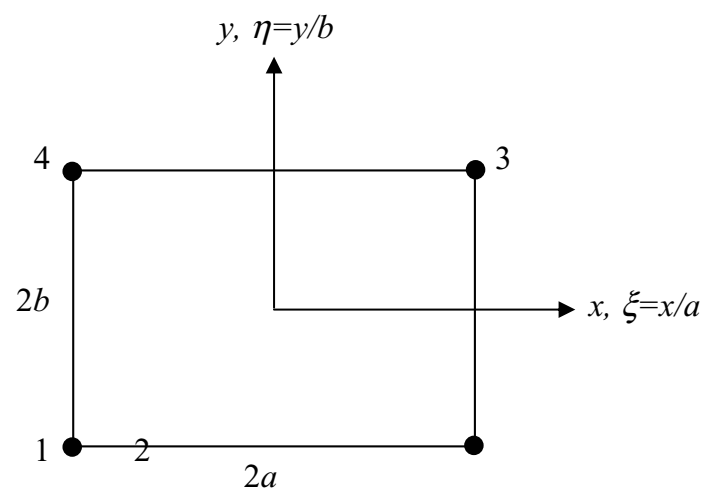

Fig. 2. A 4-noded, 12 degrees of freedom PBQ4 Mindlin plate element.

$$
\left(\frac{\gamma}{H}\right)^{2}=\frac{1-2 \nu_{s}}{2\left(1-\nu_{s}\right)} \frac{\int_{-\infty}^{+\infty} \int_{-\infty}^{+\infty}(\nabla w)^{2} d x d y}{\int_{-\infty}^{+\infty} \int_{-\infty}^{+\infty} w^{2} d x d y}
$$

The important point here is that the modulus of subgrade reaction, $k$, and the second parameter $2 t$ representing the shear deformation of the soil, are both dependent on the vertical deformation function $\phi$ and the depth of the soil $H$ as can be seen in Eq. (7). Furthermore the value of $\gamma$ varies with the displacement of the plate and the depth of the subsoil. Therefore the variables $w, k, 2 t, H$ and $\gamma$ are all connected to each other for the analysis of the plates on elastic foundation using the Modified Vlasov Model [12].

\section{Finite element modelling}

The governing equation for a plate subjected to a free vibration with no damping is

$$
[M]\{\ddot{w}\}+[K]\{w\}=0
$$

where $[K]$ is the stiffness matrix of the plate-soil system, $[M]$ is the mass matrix of the plate-soil system, $w$ and $\ddot{w}$ are the displacement and acceleration of the plate, respectively. Evaluation of the stiffness and mass matrices are given in the following sections for a plate resting on an elastic foundation.

\subsection{Evaluation of the stiffness matrix}

A 4-noded (PBQ4) quadrilateral rectangular finite element based on Mindlin theory are used to develop the element stiffness matrices (Fig. 2).

Nodal displacements at each node are

$$
w, \varphi_{x}, \varphi_{y}
$$

where $w$ is the transverse displacement, $\varphi_{x}, \varphi_{y}$ are the rotations of the normal to the undeformed middle surface. It is assumed that $w, \varphi_{x}$ and $\varphi_{y}$ vary linearly for PBQ4 over the element so that

$$
\begin{aligned}
& u=z \varphi_{y}=z \sum_{i=1}^{n} N_{i} \varphi_{y i} \\
& v=-z \varphi_{x}=-z \sum_{i=1}^{n} N_{i} \varphi_{x i} \\
& w=\sum_{i=1}^{n} N_{i} w_{i}
\end{aligned}
$$


in which $n$ is equal to 4 . So the displacement shape functions are given as

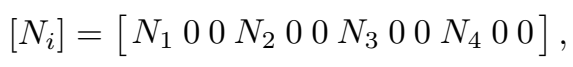

in which $N_{1}, N_{2}, N_{3}$, and $N_{4}$ are the shape functions and given in reference [13].

Substituting Eqs (15) and (16) into Eq. (6), the stiffness matrices of the plate-soil system can be evaluated as

$$
U=\frac{1}{2}\left\{w_{e}\right\}^{t}\left(\left[k_{p}\right]+\left[k_{w}\right]+\left[k_{2 t}\right]\right)\left\{w_{e}\right\}
$$

where $\left[k_{p}\right],\left[k_{w}\right]$ and $\left[k_{2 t}\right]$ are stiffness matrix of the plate, vertical deflection element stiffness matrix of the foundation and shear deformation element stiffness matrix of the foundation, respectively. $\left\{w_{e}\right\}$ is the nodal displacement vector for an element containing 12 components for PBQ4 [13].

The selective reduced integration rule on the shear terms is used to obtain the element stiffness matrix of the plate $\left[k_{p}\right]$ to avoid shear locking problem under the thin plate limit. The element stiffness matrices are not presented in the paper since the matrices takes a lot of space. The matrices are given in explicit forms in [14].

Assembling each element stiffness matrices obtained, global stiffness matrix can be evaluated as

$$
[K]=\sum_{i=1}^{n_{e}}\left(\left[k_{p}\right]+\left[k_{w}\right]+\left[k_{2 t}\right]\right)
$$

where $n_{e}$ is the number of plate finite elements. Finally the equation to be solved is

$$
[K]\{W\}=\{F\}
$$

Here $[K]$ is the global stiffness matrix, $\{W\}$ represents the global nodal displacement vector, and $\{F\}$ is the applied equivalent load vector of the system. Boundary conditions need to be applied before solving the system of equations. The effect of the infinite soil domain outside the plate is applied as equivalent stiffness parameters on the plate boundary. Equivalent forces due to surrounding soil domain on the boundary of the plate are computed as a function of the displacement on the boundary [14].

\section{Evaluation of the mass matrix}

According to Hamilton's variational principle, the total kinetic energy of the plate-soil system may be written as

$$
\pi_{k}=\frac{1}{2} \int_{\Omega}\{\dot{w}\}^{T}[\mu]\{\dot{w}\} d \Omega
$$

where $[\mu]$ is the mass density matrix and $\{\dot{w}\}$ represents the partial derivative of the vector of generalized displacement with respect to time variable. The consistent mass matrix, $[M]$, is obtained by substituting $w=N_{1} w_{e}$ into Eq. (20)

$$
[M]=\int_{\Omega}\left\{N_{1}\right\}^{T}[\mu]\left\{N_{1}\right\} d \Omega
$$

The mass matrix for the plate-soil system needs to be analyzed. The matrix $[\mu]$ in Eq. (21) is a square symmetric matrix of the form

$$
[\mu]=\left[\begin{array}{ccc}
\rho_{p} h+\frac{1}{3} \rho_{s} H & 0 & 0 \\
0 & \frac{1}{12} \rho_{p} h^{3} & 0 \\
0 & 0 & \frac{1}{12} \rho_{p} h^{3}
\end{array}\right]
$$

where $\rho_{p}$ is the plate density, $h$ is the plate thickness and $\rho_{s}$ is the mass density of the soil. The following expression can be written for each finite piece

$$
\left[N_{1}\right]=\left[\begin{array}{c}
N \\
\frac{d N}{d y} \\
\frac{d N}{d x}
\end{array}\right] .
$$


The consistent mass matrix of the plate and the soil can be evaluated after substituting Eq. (23) into Eq. (21). By assembling the element mass matrix obtained, the system mass matrix is evaluated [4]. The element mass matrix is given into sub matrices of $6 \times 6$ as follows;

$$
[M]=\frac{1}{9} a b\left[\begin{array}{l}
{\left[M_{1}\right]\left[M_{2}\right]} \\
\text { sym. }\left[M_{1}\right]
\end{array}\right]
$$

These sub matrices are

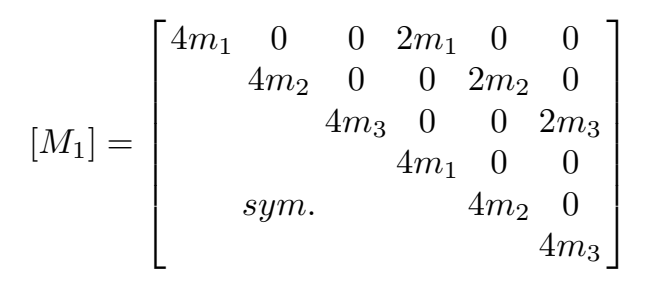

and

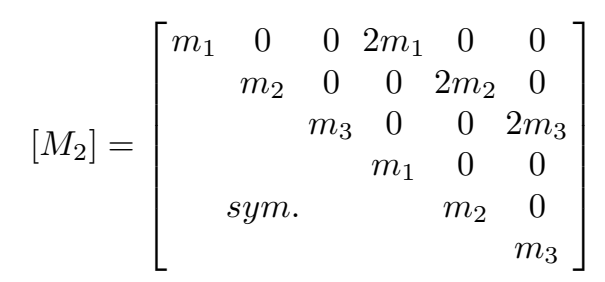

where $m_{1}=\rho_{p} h+\frac{1}{3}\left(\rho_{s} H\right)$ and $m_{2}=m_{3}=\frac{1}{12} \rho_{p} h^{3}$.

As mentioned before, the governing equation for a plate subjected to a free vibration with no damping is represented with Eq. (13). After substituting $w=W \sin \omega t$ into this equation, one can obtain

$$
\left([K]-\omega^{2}[M]\right)\{W\}=0
$$

where $\{W\}$ is a vector of mode shape of vibration and $\lambda\left(=\omega^{2}, \omega\right.$ is the circular frequency) is the frequency parameter. The eigenvalue solution of this equation yields frequency parameters and the corresponding mode shapes.

\section{Numerical examples}

\subsection{Data for numerical examples}

A parametric study for the free vibration analysis of the plates on elastic foundations is carried out using the various values of $H, l_{y} / l_{x}, H / l_{y}$ and $\gamma$. The values of the vertical deformation parameter, $\gamma$, are taken to be 1,2 , $3,4,5,6,7$ and 8 . The depths, $H$, of the subsoil are taken to be 5,10 and $15 \mathrm{~m}$ for each $\gamma$ parameter considered, and the ratios $l_{y} / l_{x}$ used are $1.0 ; 1.5$ and 2.0 while $l_{x}$ remains constant for each subsoil depth. In the calculation of the mass matrix, the mass densities of plate and subsoil are taken to be 2500 and $1700 \mathrm{~kg} / \mathrm{m}^{3}$, respectively. The properties of the plate-soil system are as follows: The length of the plate in the $x$ direction, $10 \mathrm{~m}$; the thickness of the plate, $0.5 \mathrm{~m}$; the modulus of elasticity of the plate, $27.10^{9} \mathrm{~N} / \mathrm{m}^{2}$; the modulus of elasticity of the subsoil, $2.10^{7}$ $\mathrm{N} / \mathrm{m}^{2}$; the Poisson's ratio of the plate, 0.20 and the Poisson's ratio of the subsoil, 0.25.

The convergence of the frequency parameters is checked for different mesh sizes for the sake of the accuracy of the results. It is concluded that the result is accurate enough when equally spaced 10 elements for $10 \mathrm{~m}$ length is used in each direction. The element length is kept constant for different dimension of the plate. 
Table 1

First 10 frequency parameters of plates on elastic foundations for different values of $H, H / l_{y}$ and $\gamma$

\begin{tabular}{|c|c|c|c|c|c|c|c|c|c|c|c|c|c|}
\hline \multirow{2}{*}{$\gamma$} & \multirow{2}{*}{$H(m)$} & \multirow{2}{*}{$l_{y}(m)$} & \multirow{2}{*}{$H / l_{y}$} & \multicolumn{10}{|c|}{ Frequency parameters } \\
\hline & & & & $\lambda_{1}$ & $\lambda_{2}$ & $\lambda_{3}$ & $\lambda_{4}$ & $\lambda_{5}$ & $\lambda_{6}$ & $\lambda_{7}$ & $\lambda_{8}$ & $\lambda_{9}$ & $\lambda_{10}$ \\
\hline \multirow[t]{12}{*}{1} & 5 & 20 & 0.250 & 157.40 & 199.52 & 276.48 & 293.43 & 358.01 & 513.91 & 552.68 & 814.61 & 961.58 & 1019.18 \\
\hline & & 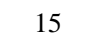 & 0.333 & 164.30 & 234.66 & 287.07 & 410.52 & 424.83 & 794.03 & 837.51 & 975.35 & 1203.04 & 1713.59 \\
\hline & & 10 & 0.500 & 180.84 & 309.90 & 309.90 & 593.09 & 788.05 & 947.46 & 1582.60 & 1582.60 & 3665.71 & 3665.71 \\
\hline & & 5 & 1.000 & 229.32 & 379.64 & 573.38 & 958.87 & 1307.44 & 3615.73 & 3724.44 & 7299.35 & 8200.07 & 9281.76 \\
\hline & 10 & 20 & 0.500 & 60.62 & 91.90 & 151.37 & 165.90 & 216.88 & 333.92 & 365.67 & 543.83 & 660.94 & 699.49 \\
\hline & & - & 0.667 & 65.30 & 118.22 & 160.58 & 259.79 & 271.03 & 549.24 & 565.62 & 663.74 & 836.63 & 1187.99 \\
\hline & & 10 & 000 & 75.86 & 180.61 & 180.61 & 408.02 & 550.37 & 654.27 & 1124.80 & 1124.80 & 2423.80 & 2423.80 \\
\hline & & 5 & 2.000 & 107.77 & 242.73 & 430.36 & 714.08 & 989.53 & 2568.39 & 2569.64 & 4818.60 & 6266.65 & 6542.91 \\
\hline & 15 & 20 & 0.750 & 36.59 & 64.18 & 116.19 & 130.96 & 117.05 & 278.27 & 310.28 & 447.34 & 564.15 & 586.18 \\
\hline & & 15 & 1.000 & 40.38 & 87.18 & 125.13 & 215.88 & 227.29 & 468.95 & 473.87 & 558.10 & 704.86 & 1007.20 \\
\hline & & 10 & 500 & 48.65 & 144.63 & 144.63 & 354.88 & 478.71 & 544.75 & 973.38 & 973.38 & 1927.33 & 1927.33 \\
\hline & & 5 & 3.000 & 73.93 & 205.73 & 391.24 & 645.60 & 897.92 & 2150.77 & 2215.89 & 3807.27 & 5158.90 & 5279.93 \\
\hline \multirow[t]{12}{*}{2} & 5 & 20 & 0.250 & 174.53 & 212.95 & 280.31 & 296.93 & 354.44 & 500.80 & 535.62 & 783.99 & 924.71 & 975.47 \\
\hline & & 15 & & 180.95 & 244.28 & 289.48 & 401.90 & 414.75 & 760 & 803.14 & 939.76 & 114 & 164 \\
\hline & & 10 & 00 & 196.42 & 309.07 & 309.07 & 566.93 & 752.13 & 901.45 & 1507.75 & 1507.75 & 3562.16 & 3562.16 \\
\hline & & 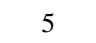 & 1.000 & 240.84 & 368.52 & 527.50 & 897.72 & 1217.65 & 3457.59 & 3590.33 & 6400.45 & 7098.87 & 9018.61 \\
\hline & 10 & 20 & 0.500 & 64.08 & 91.27 & 141.85 & 154.68 & 198.11 & 303.03 & 329.27 & 495.47 & 596.92 & 633.44 \\
\hline & & 15 & & 68.28 & 113.96 & 149.42 & 235.03 & 244.36 & & 513.06 & 602.73 & & 108 \\
\hline & & 10 & . & 77.92 & 165.77 & 165.77 & 361.19 & 489.29 & & 1009.86 & 1009.86 & & \\
\hline & & 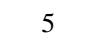 & 2.000 & 106.54 & 216.00 & 364.47 & 620.33 & 858.63 & 2326.83 & 2364.97 & 4553.11 & 5850.48 & 6140.25 \\
\hline & 15 & 20 & 0.750 & 37.20 & 60.28 & 103.69 & 115.81 & 153.87 & 242.14 & 266.80 & 394.80 & 488.45 & 513.32 \\
\hline & & 1 & & 40.52 & 79.55 & 110 & & 24 & & & & & \\
\hline & & 10 & 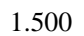 & 47.87 & 126.20 & 126.20 & 300 & 406.67 & & 838.55 & 838.55 & 177 & 177 \\
\hline & & E & 3.000 & 70.09 & 174.04 & 319.07 & 536.55 & 746.40 & 1906.95 & 1922.41 & 3519.21 & 4639.67 & 4816.77 \\
\hline \multirow[t]{12}{*}{3} & 5 & 20 & 250 & 5.60 & 251.81 & 313.08 & 329.03 & 381.87 & 520 & 553.19 & 791.05 & 92 & 972.83 \\
\hline & & & & 1.77 & 280.79 & 26 & & & & & & & \\
\hline & & 10 & 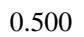 & 683 & 338.65 & 338.65 & 578 & 756.34 & 896 & 148 & 1483.24 & & 3513.22 \\
\hline & & 5 & 1.000 & 279.38 & 391.16 & 525.02 & 883.51 & 1183.20 & 3372.75 & 3521.26 & 5011.85 & 6977.87 & 8857.46 \\
\hline & 10 & 20 & 0500 & 75.17 & 99.60 & 143.85 & 155.12 & 193.09 & 288.13 & 310.75 & 467.01 & 557.35 & 591.16 \\
\hline & & & & & 119.77 & & & & & & & & \\
\hline & & 10 & & 000 & 163.80 & 163.80 & & & & & 932.03 & & \\
\hline & & 5 & 2.000 & 115.07 & 205.33 & 323.76 & 558.63 & 769.14 & 2156.11 & 2219.57 & 4355.23 & 5208.32 & 5551.10 \\
\hline & 15 & 20 & 0750 & 41.74 & 61.60 & 98.60 & 108.44 & 140.48 & 217 & 237.44 & 357.39 & 433.69 & 459.48 \\
\hline & & & & & & & & & & & & & \\
\hline & & 10 & & & 116 & & & & & & & & \\
\hline & & 5 & 3.000 & 71.91 & 154.37 & 267.26 & 456.19 & 633.11 & 1701.91 & 1721.82 & 3290.59 & 4248.41 & 4452.77 \\
\hline \multirow[t]{12}{*}{4} & 5 & 20 & 0.250 & 268.83 & 303.87 & 361.68 & 377 & 427.30 & & 592.73 & 823.70 & & 999.75 \\
\hline & & & & & & & & & & & & & \\
\hline & & 10 & & 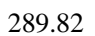 & & & & & & & & & \\
\hline & & 5 & 1.000 & 331.60 & 433.92 & 552.48 & 904.12 & 1191.99 & 3350.22 & 3508.99 & 4149.69 & 6931.97 & 8792.79 \\
\hline & 10 & 20 & 0.5 & 9 & 11 & 15 & 16 & 56 & & 30 & 457.45 & & \\
\hline & & 15 & & & & & & & & & & & 975.47 \\
\hline & & 10 & & & & & & & & & & & \\
\hline & & 5 & 2.000 & 128.93 & 207.48 & 307.17 & 530.25 & 724.31 & 2065.28 & 2142.22 & 4142.13 & 4241.58 & 5387.62 \\
\hline & 15 & 20 & 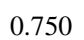 & 48. & 66.46 & 99.45 & 107.97 & 136.35 & & 223.67 & 337.46 & 40 & 429.55 \\
\hline & & 1 & & & & & & & & & 409.80 & & 734.92 \\
\hline & & 10 & & & & & & & & & & & \\
\hline & & 5 & 3.000 & 77.19 & 146.49 & 238.95 & 411.76 & 568.96 & 1577.00 & 1615.80 & 3150.98 & 4026.76 & 4172.78 \\
\hline \multirow[t]{8}{*}{5} & 5 & 20 & 0.250 & 325.98 & 360.34 & 416.01 & 431.18 & 479.69 & 610.39 & 641.52 & 867.94 & 1001.87 & 1040.53 \\
\hline & & 15 & & & & & & & & & & & \\
\hline & & 10 & & & 438 & & & 831.74 & & & 1531.29 & & 3534.10 \\
\hline & & 5 & 1.000 & 388.24 & 484.69 & 593.65 & 941.29 & 1222.01 & 3351.95 & 3526.22 & 3629.64 & 6927.32 & 8779.44 \\
\hline & 10 & 20 & 500 & 06.75 & 28.73 & 166.67 & 176.47 & 13 & 294 & 313.84 & 40 & & 569.35 \\
\hline & & 15 & & & & 171.82 & & & & & & & \\
\hline & & 10 & & & & & & & & & 878.95 & & \\
\hline & & 5 & 2.000 & 144.73 & 216.01 & 303.95 & 520.42 & 704.64 & 2019.20 & 2103.60 & 3464.43 & 4178.68 & 5300.30 \\
\hline
\end{tabular}


Table 1, continued

\begin{tabular}{|c|c|c|c|c|c|c|c|c|c|c|c|c|c|}
\hline \multirow{2}{*}{$\gamma$} & \multirow{2}{*}{$H(m)$} & \multirow{2}{*}{$l_{y}(m)$} & \multirow{2}{*}{$H / l_{y}$} & \multicolumn{10}{|c|}{ Frequency parameters } \\
\hline & & & & $\lambda_{1}$ & $\lambda_{2}$ & $\lambda_{3}$ & $\lambda_{4}$ & $\lambda_{5}$ & $\lambda_{6}$ & $\lambda_{7}$ & $\lambda_{8}$ & $\lambda_{9}$ & $\lambda_{10}$ \\
\hline & 15 & 20 & 0.750 & 55.95 & 72.89 & 103.32 & 111.10 & 137.23 & 203.21 & 218.76 & 328.11 & 390.78 & 414.24 \\
\hline & & 15 & 1.000 & 58.69 & 86.81 & 107.63 & 159.29 & 164.91 & 319.83 & 337.64 & 396.73 & 491.77 & 707.25 \\
\hline & & 10 & 1.500 & 65.14 & 11689 & 116.89 & 234.82 & 317.05 & 383.64 & 651.30 & 651.30 & 1530.49 & 1530.49 \\
\hline & & 5 & 3.000 & 83.89 & 145.07 & 224.66 & 388.50 & 533.93 & 1507.68 & 1556.66 & 3068.07 & 3441.89 & 3902.95 \\
\hline \multirow[t]{12}{*}{6} & 5 & 20 & 0.250 & 384.18 & 418.10 & 472.32 & 487.31 & 534.71 & 663.33 & 694.18 & 917.43 & 1051.04 & 1087.79 \\
\hline & & 15 & 0.333 & 390.15 & 444.50 & 479.34 & 573.34 & 584.92 & 893.12 & 930.35 & 1066.68 & 1240.34 & 1724.11 \\
\hline & & 10 & 0.500 & 405.02 & 494.15 & 494.15 & 712.19 & 881.09 & 1007.88 & 1573.94 & 1573.94 & 2940.83 & 3569.35 \\
\hline & & 5 & 1.000 & 446.12 & 538.65 & 641.15 & 986.29 & 1262.33 & 3243.32 & 3427.42 & 3558.19 & 6944.28 & 8792.04 \\
\hline & 10 & 20 & 0.500 & 123.66 & 145.06 & 181.34 & 190.82 & 222.13 & 304.47 & 323.70 & 464.90 & 545.61 & 572.72 \\
\hline & & 15 & 0.667 & 127.30 & 16219 & 186.19 & 248.06 & 255.17 & 450.06 & 474.65 & 555.12 & 669.82 & 960.37 \\
\hline & & 10 & 1.000 & 136.16 & 196.51 & 196.51 & 338.70 & 444.47 & 527.70 & 875.33 & 875.33 & 2079.67 & 2079.67 \\
\hline & & 5 & 2.000 & 161.21 & 227.67 & 307.79 & 520.22 & 698.13 & 1996.11 & 2085.19 & 3011.31 & 4143.42 & 5251.98 \\
\hline & 15 & 20 & 0.750 & 63.75 & 80.00 & 108.69 & 116.03 & 140.67 & 203.77 & 218.51 & 324.62 & 384.81 & 406.96 \\
\hline & & 15 & 1.000 & 66.43 & 93.26 & 112.67 & 161.34 & 166.71 & 315.12 & 333.15 & 391.19 & 481.18 & 692.61 \\
\hline & & 10 & 1.500 & 72.81 & 121.18 & 121.18 & 232.48 & 311.94 & 376.03 & 634.98 & 634.98 & 1505.58 & 1505.58 \\
\hline & & 5 & 3.000 & 91.17 & 147.02 & 218.01 & 376.47 & 514.41 & 1467.20 & 1522.20 & 2949.38 & 3016.67 & 3829.36 \\
\hline \multirow[t]{12}{*}{7} & 5 & 20 & 0.250 & 442.66 & 476.28 & 529.45 & 544.32 & 590.93 & 718.05 & 748.74 & 969.66 & 1103.14 & 1138.47 \\
\hline & & 15 & 0.333 & 448.61 & 502.30 & 536.30 & 628.83 & 640.37 & 945.69 & 982.10 & 1118.64 & 1289.44 & 1772.52 \\
\hline & & 10 & 0.500 & 463.47 & 550.74 & 550.74 & 765.74 & 933.28 & 1057.91 & 1621.46 & 1621.46 & 2717.41 & 3611.49 \\
\hline & & 5 & 1.000 & 504.39 & 594.11 & 691.99 & 1035.43 & 1308.19 & 3033.78 & 3448.24 & 3598.23 & 6973.41 & 8818.84 \\
\hline & 10 & 20 & 0.500 & 140.73 & 161.72 & 196.81 & 206.08 & 236.45 & 316.97 & 335.84 & 474.57 & 554.48 & 580.25 \\
\hline & & 15 & 0.667 & 144.34 & 178.41 & 201.46 & 261.49 & 268.49 & 459.61 & 483.69 & 564.06 & 675.31 & 964.31 \\
\hline & & 10 & 1.000 & 153.16 & 211.31 & 211.31 & 349.56 & 453.68 & 534.65 & 878.19 & 878.19 & 2076.45 & 2076.45 \\
\hline & & 5 & 2.000 & 177.98 & 241.04 & 315.60 & 525.39 & 698.95 & 1985.46 & 2077.96 & 2691.83 & 4123.91 & 5224.87 \\
\hline & 15 & 20 & 0.750 & 71.68 & 87.46 & 114.89 & 121.95 & 145.54 & 206.62 & 220.85 & 324.53 & 383.26 & 404.29 \\
\hline & & 15 & 1.000 & 74.31 & 100.24 & 118.64 & 165.23 & 170.44 & 314.41 & 332.36 & 389.88 & 476.20 & 685.17 \\
\hline & & 10 & 1.500 & 80.65 & 126.63 & 126.63 & 233.36 & 310.93 & 372.99 & 623.36 & 623.36 & 1490.68 & 1490.68 \\
\hline & & 5 & 3.000 & 98.75 & 150.84 & 215.75 & 370.72 & 503.53 & 1442.46 & 1501.37 & 2598.73 & 2983.32 & 3782.88 \\
\hline \multirow[t]{12}{*}{8} & 5 & 20 & 0.250 & 501.24 & 534.63 & 587.00 & 601.79 & 647.81 & 773.81 & 804.38 & 1023.52 & 1156.97 & 1191.19 \\
\hline & & 15 & 0.333 & 507.17 & 560.37 & 593.73 & 685.16 & 696.67 & 999.87 & 1035.61 & 1172.34 & 1340.99 & 1823.60 \\
\hline & & 10 & 0.500 & 522.03 & 607.91 & 607.91 & 820.64 & 987.14 & 1110.14 & 1671.89 & 1671.89 & 2564.26 & 3657.82 \\
\hline & & 5 & 1.000 & 562.81 & 650.43 & 744.83 & 1087.04 & 1357.38 & 2881.57 & 3488.43 & 3643.11 & 7009.99 & 8854.12 \\
\hline & 10 & 20 & 0.500 & 157.87 & 178.57 & 212.76 & 221.89 & 251.54 & 330.72 & 349.35 & 486.18 & 565.63 & 590.31 \\
\hline & & 15 & 0.667 & 161.45 & 194.93 & 217.25 & 275.93 & 282.85 & 471.22 & 494.85 & 575.22 & 683.88 & 971.88 \\
\hline & & 10 & 1.000 & 170.26 & 226.77 & 226.77 & 362.13 & 465.05 & 544.25 & 884.95 & 884.95 & 2078.61 & 2078.61 \\
\hline & & 5 & 2.000 & 194.91 & 255.44 & 325.87 & 533.80 & 704.19 & 1981.95 & 2077.41 & 2456.96 & 4114.06 & 5210.26 \\
\hline & 15 & 20 & 0.750 & 76.58 & 95.11 & 121.60 & 128.46 & 151.29 & 210.88 & 224.75 & 326.55 & 384.37 & 404.47 \\
\hline & & 15 & 1.000 & 82.28 & 107.54 & 125.18 & 170.25 & 175.36 & 316.12 & 333.86 & 391.12 & 474.68 & 682.06 \\
\hline & & 10 & 1.500 & 88.58 & 132.79 & 132.79 & 236.21 & 312.40 & 372.81 & 622.37 & 622.37 & 1481.91 & 1481.91 \\
\hline & & 5 & 3.000 & 106.50 & 155.81 & 216.21 & 368.76 & 497.87 & 1426.99 & 1488.65 & 2337.65 & 2961.02 & 3752.25 \\
\hline
\end{tabular}

\subsection{Results}

The first ten frequency parameters of plates considered for several subsoil depths, plate dimensions, their ratio and the value of the vertical deformation parameter within the soil are presented in Table 1 . The variation of the first six frequency parameters with various values of $l_{y} / l_{x}$ for three different values of subsoil depth are calculated and plotted in Figs 3-6 for $\gamma=1,3,5,7$ respectively, in order to show the effects of the changes in these parameters better.

As seen from Table 1 and Figs 3-6 the values of the frequency parameters for a constant value of $H$ and $\gamma$ decrease as $l_{y} / l_{x}$ ratio increases. The values of the frequency parameters for a constant value of $l_{y} / l_{x}$ and $\gamma$ decrease as the value of $H$ increases but the values of the frequency parameter for a constant value of $H$ and $\gamma$ increase as $H / l_{y}$ ratio increases. This behavior understandable for a plate on an elastic foundation with a larger subsoil depth becomes more flexible and has smaller frequency parameters.

It should be noted that the decrease in the frequency parameters with increasing $l_{y} / l_{x}$ ratios for a constant value of $H$ and $\gamma$ gets larger for larger values of the frequency parameters. 


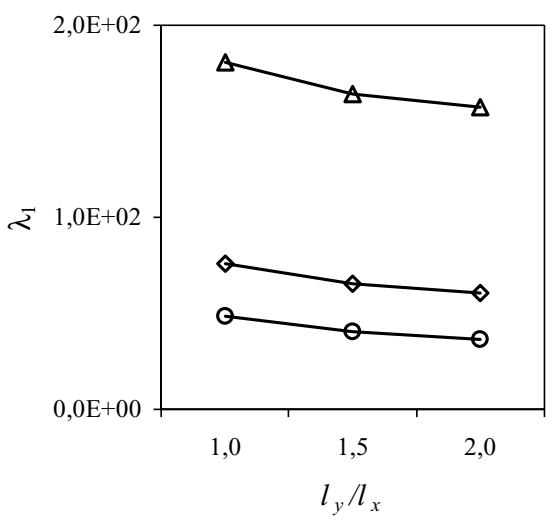

(a)

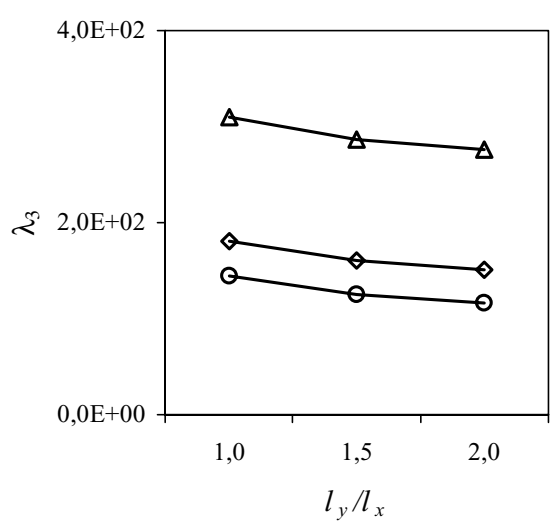

(c)

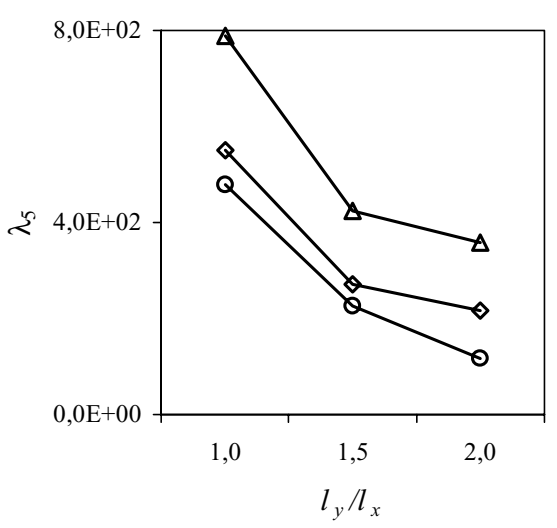

(e)

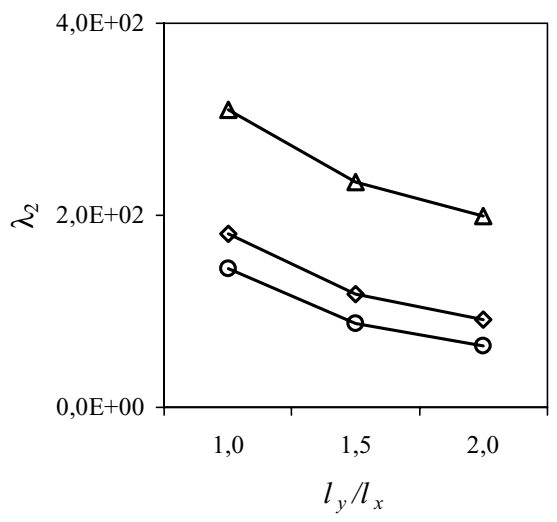

(b)

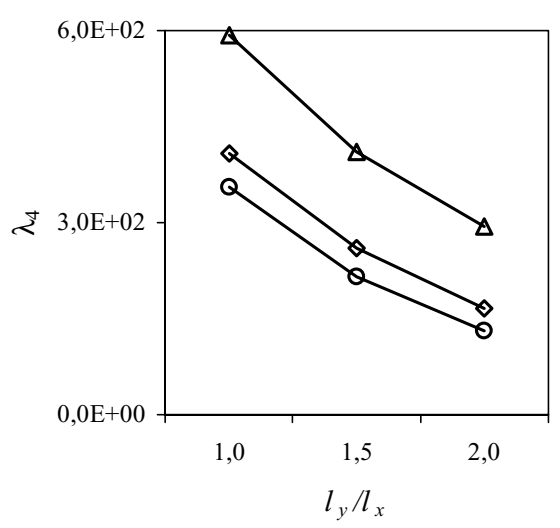

(d)

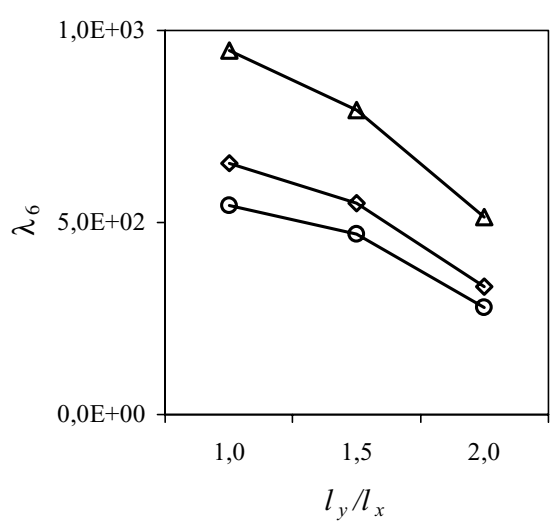

(f)

Fig. 3. The variation of the first six frequency parameters of the plate on elastic foundation with various values of $l_{y} / l_{x}$ ratio and $H$ for $\gamma=1$. $-\Delta-, H=5 \mathrm{~m} ;-\diamond-, H=10 \mathrm{~m} ;--_{-}, H=15 \mathrm{~m}$. 


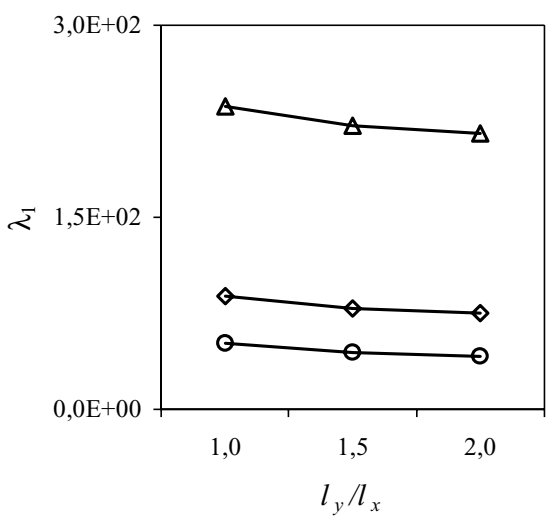

(a)

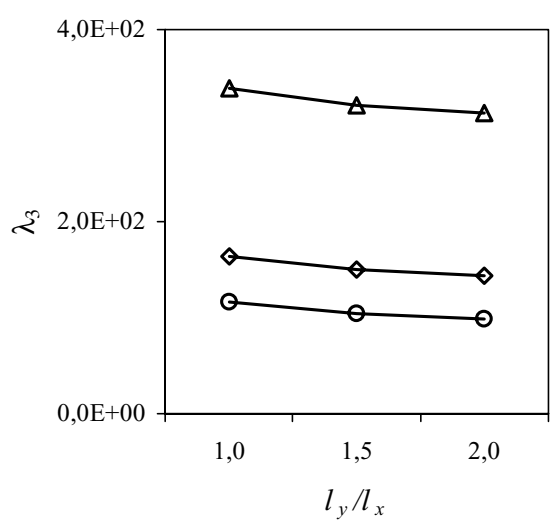

(c)

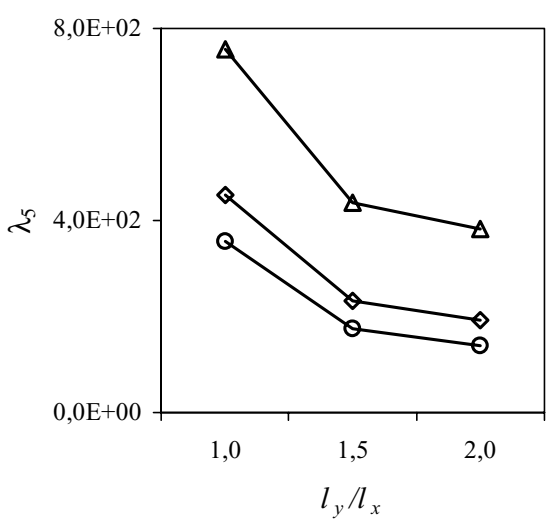

(e)

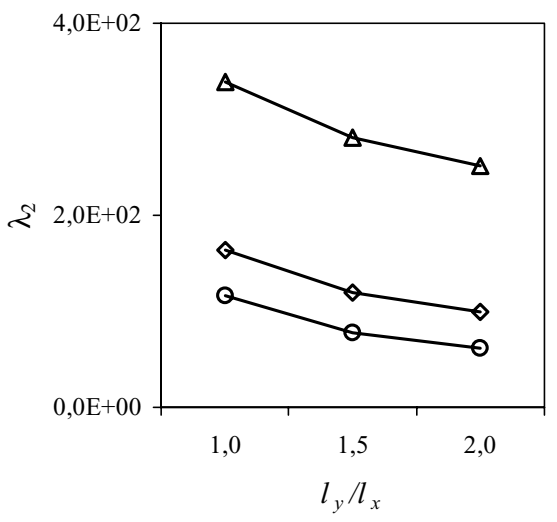

(b)

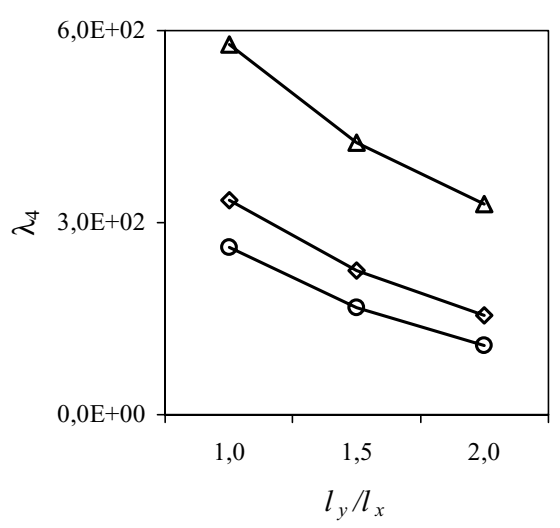

(d)

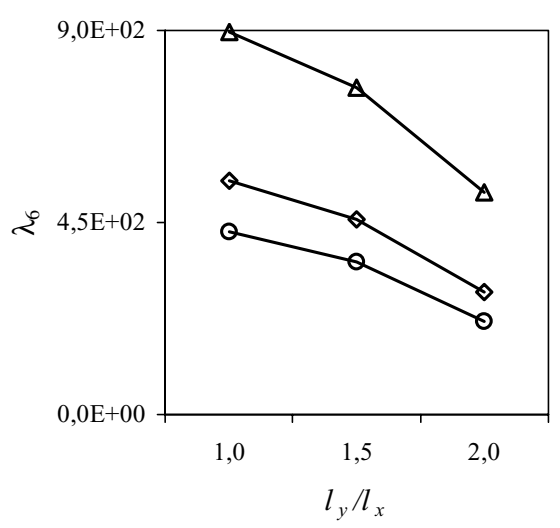

(f)

Fig. 4. The variation of the first six frequency parameters of the plate on elastic foundation with various values of $l_{y} / l_{x}$ ratio and $H$ for $\gamma=3$. $-\Delta-, H=5 \mathrm{~m} ;-\diamond-, H=10 \mathrm{~m} ;--_{-}, H=15 \mathrm{~m}$. 


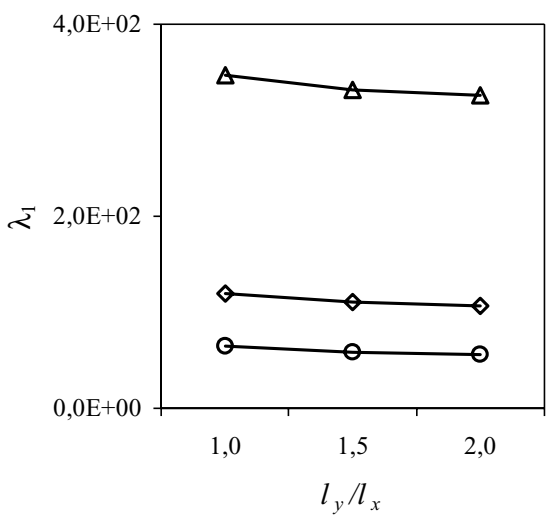

(a)

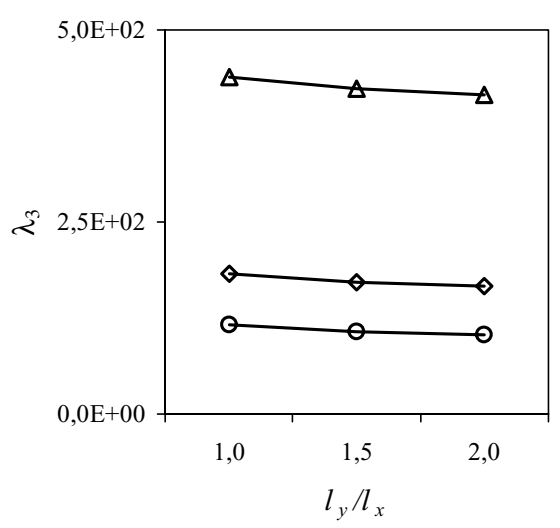

(c)

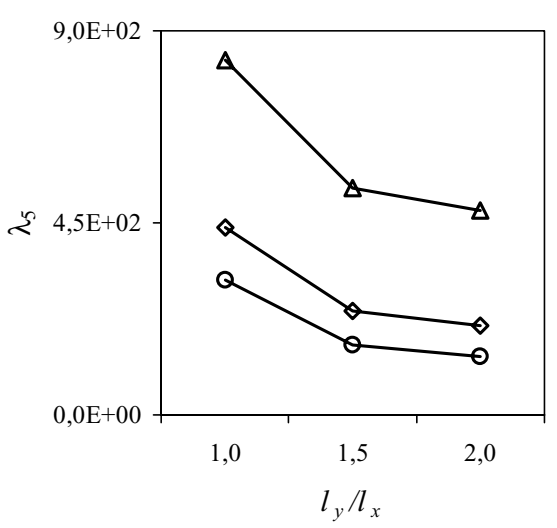

(e)

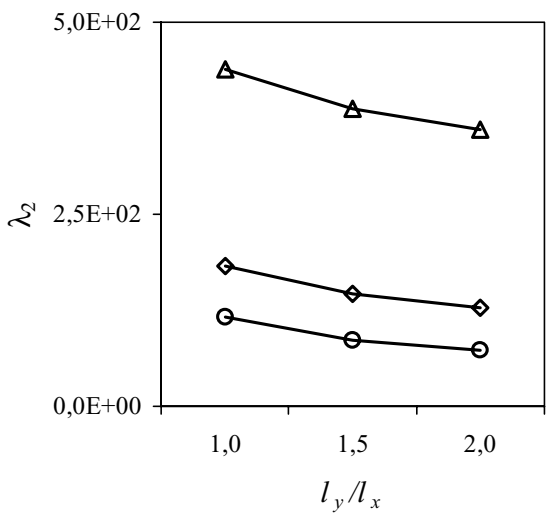

(b)

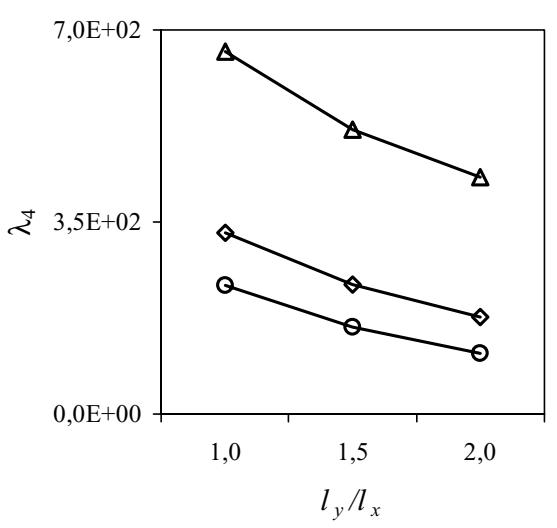

(d)

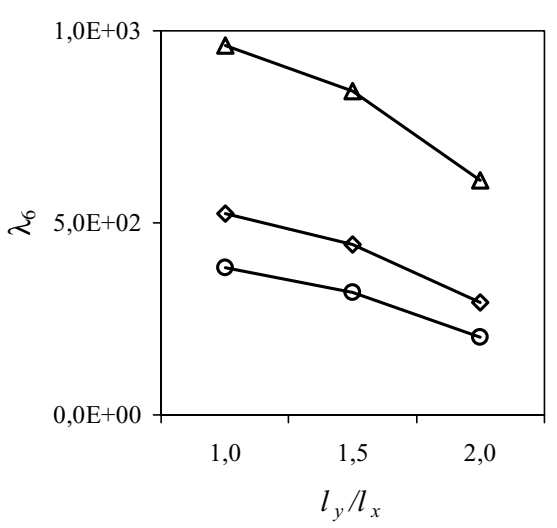

(f)

Fig. 5. The variation of the first six frequency parameters of the plate on elastic foundation with various values of $l_{y} / l_{x}$ ratio and $H$ for $\gamma=5$. $-\Delta-, H=5 \mathrm{~m} ;-\diamond-, H=10 \mathrm{~m} ;-\mathrm{o}_{-}, H=15 \mathrm{~m}$. 


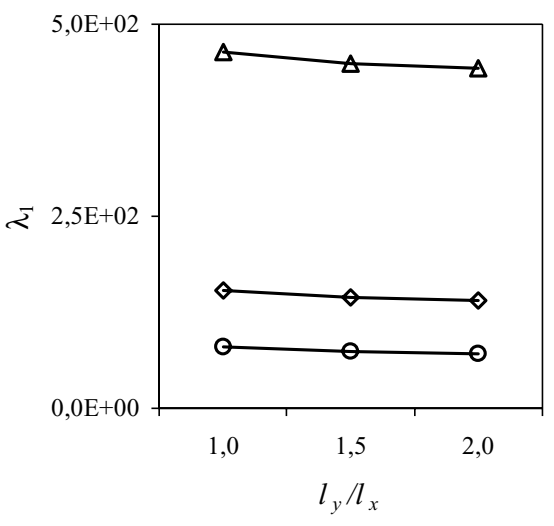

(a)

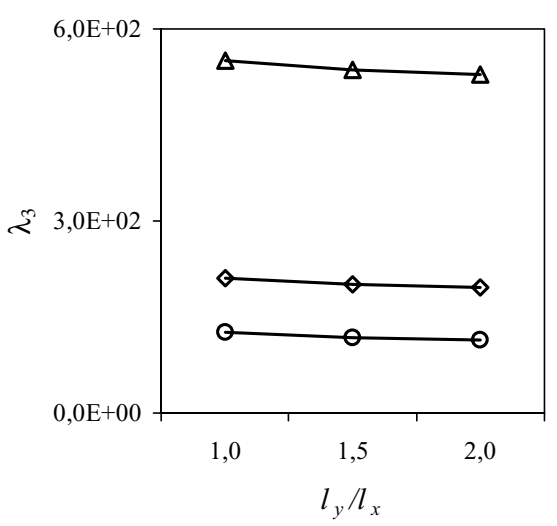

(c)

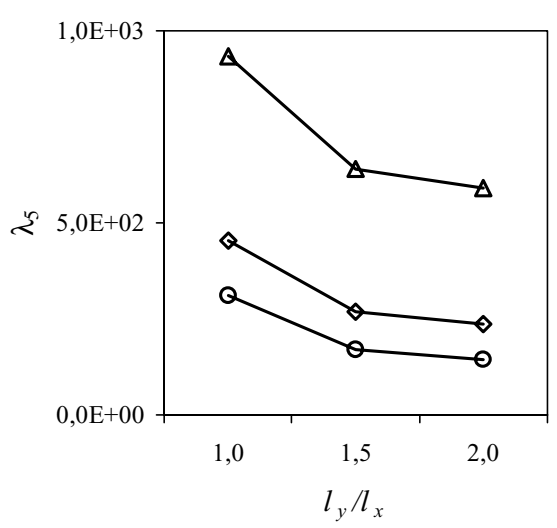

(e)

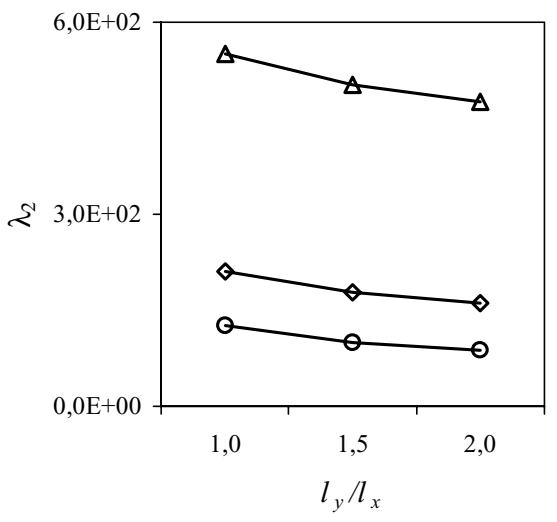

(b)

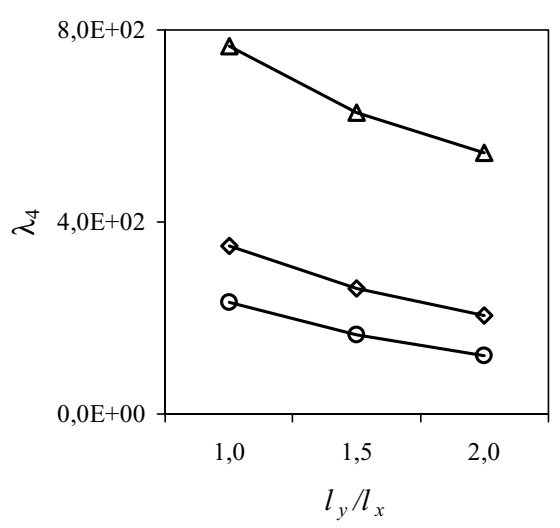

(d)

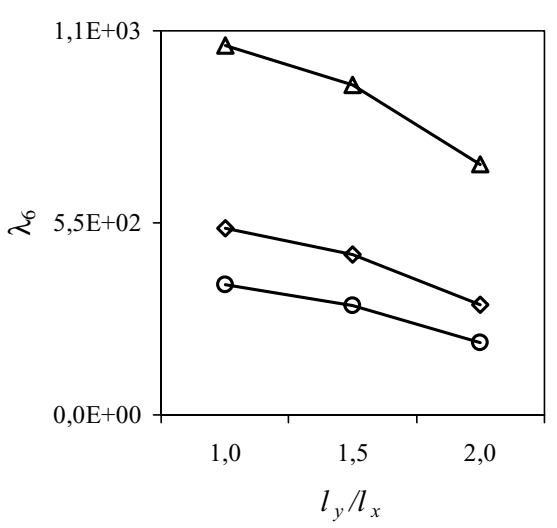

(f)

Fig. 6. The variation of the first six frequency parameters of the plate on elastic foundation with various values of $l_{y} / l_{x}$ ratio and $H$ for $\gamma=7$. $-\Delta-, H=5 \mathrm{~m} ;-\diamond-, H=10 \mathrm{~m} ;-\mathrm{o}-, H=15 \mathrm{~m}$. 


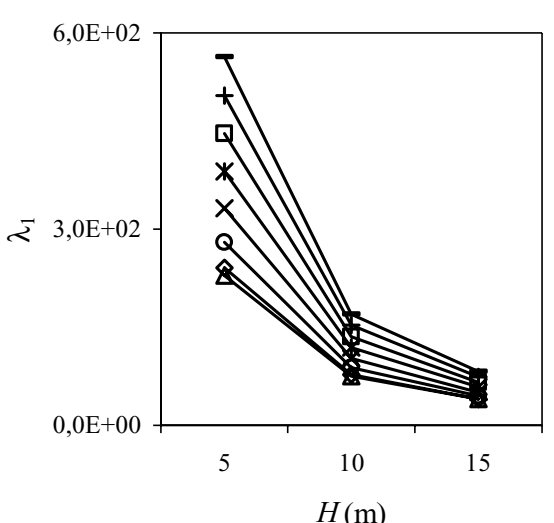

(a)

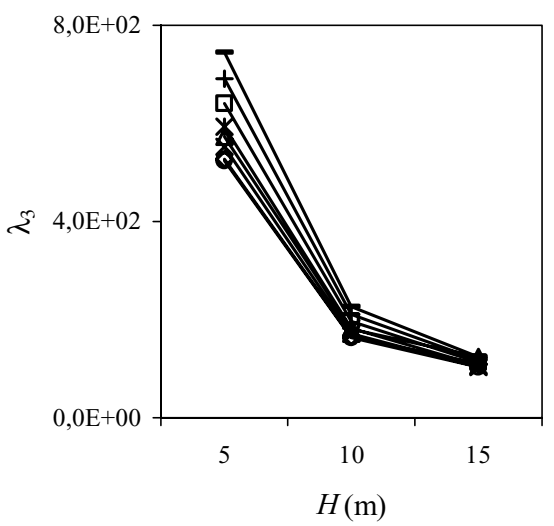

(c)

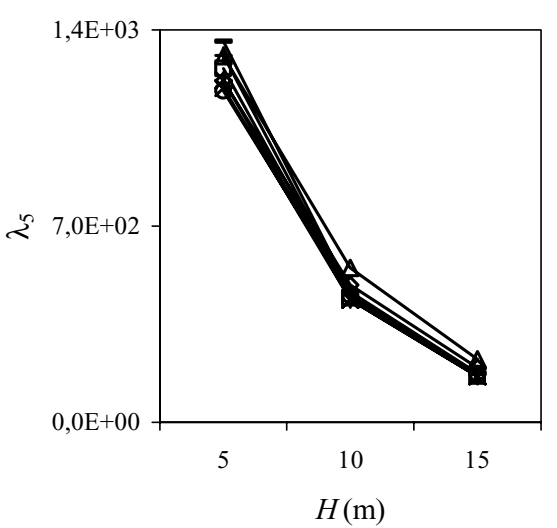

(e)

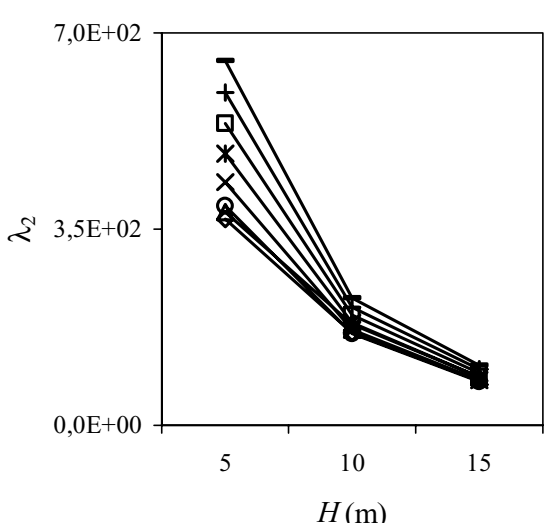

(b)

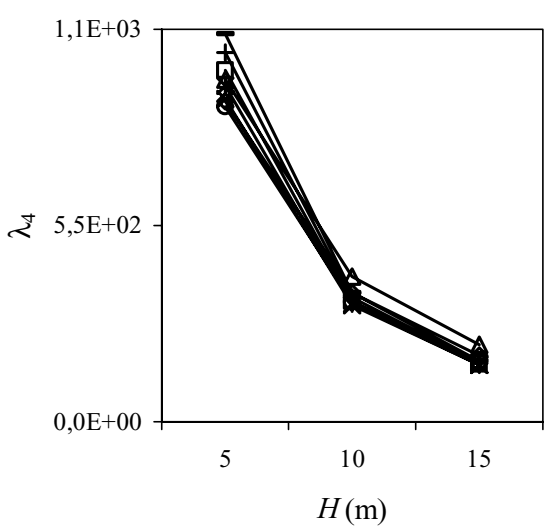

(d)

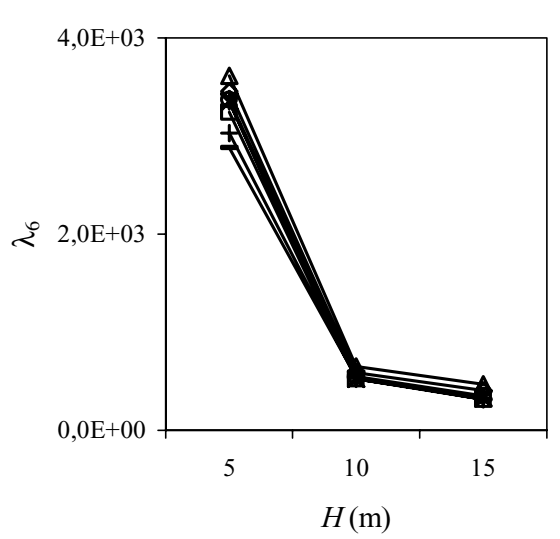

(f)

Fig. 7. The effect of different value of $H$ and $\gamma$ on the first six frequency parameters of the plate on elastic foundation for $H / l_{y}=1.000$. $-\Delta-$, $\gamma=1 ;--_{-}, \gamma=2 ;-0-, \gamma=3 ;-\times-, \gamma=4 ;-_{-}^{*}, \gamma=5 ;-\square-, \gamma=6 ;-+-, \gamma=7 ;-, \gamma=8$. 


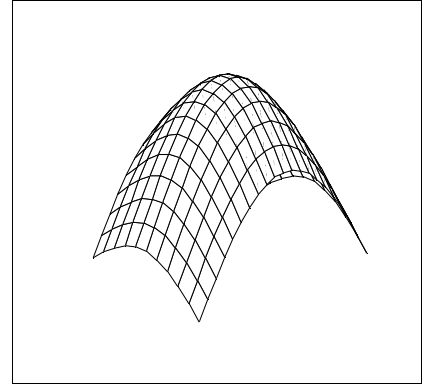

(a) $\lambda_{1}=157,40$

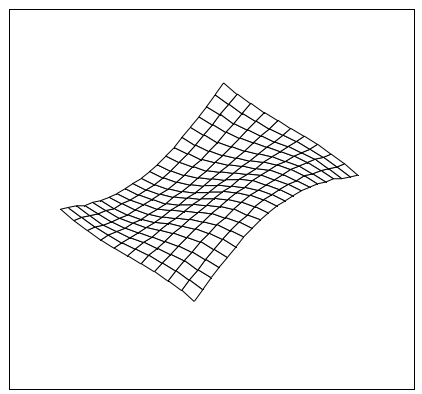

(c) $\lambda_{3}=276,48$

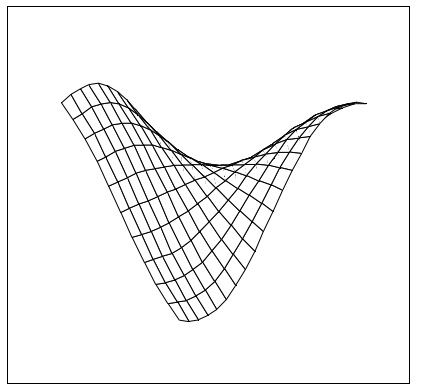

(e) $\lambda_{5}=358,01$

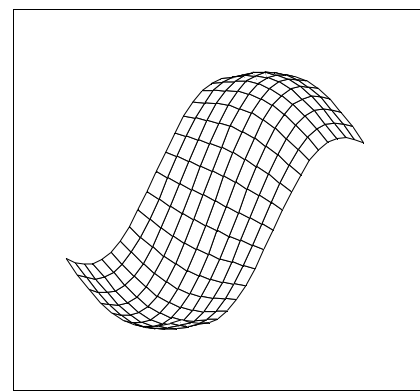

(b) $\lambda_{2}=199,52$

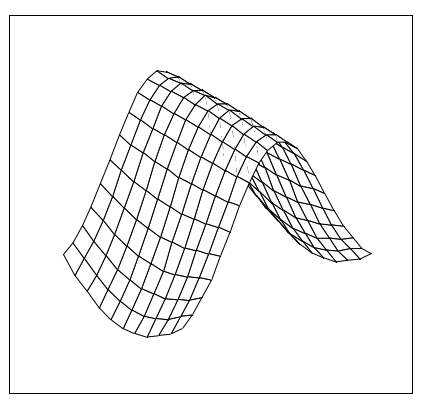

(d) $\lambda_{4}=293,43$

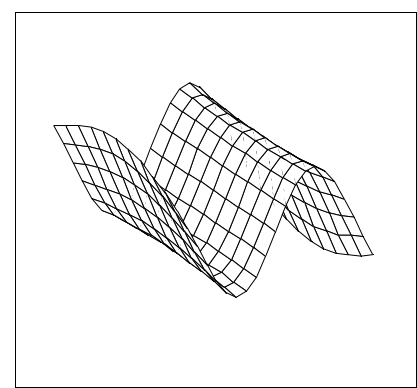

(f) $\lambda_{6}=513,91$

Fig. 8. First six mode shapes of the plate on elastic foundations for $\gamma=1, H=5 \mathrm{~m}$, and $l_{y} / l_{x}=2.00$. (a) The first mode shape; (b) The second mode shape; (c) The third mode shape; (d) The fourth mode shape; (e) The fifth mode shape; and (f) The sixth mode shape.

The decrease in the frequency parameters with increasing $l_{y} / l_{x}$ ratio for a constant value of $H$ and $\gamma$ gets larger for smaller values of $l_{y} / l_{x}$.

The change occurring in the frequency parameters with increasing subsoil depth for a constant value of $l_{y} / l_{x}$ or $H / l_{y}$ ratio is larger than the change occurring in the frequency parameters with increasing $H / l_{y}$ or $l_{y} / l_{x}$ ratio for a constant value of $H$.

These observations indicate that the effects of the change in the subsoil depth on the frequency parameters of the plate on elastic foundation are always larger than those of the change in the other parameters considered in this study.

As can also be seen from Fig. 7, curves for a constant value of $H / l_{y}$ get fairly closer to each other as the value of $H$ increases. This shows that the curves of the frequency parameters will almost coincide with each other when the value of $H$ increases more. In other words, an increase in the subsoil depth will not affect the frequency parameters after a certain value of $H$. In addition as seen from table, variations occurring in the frequency parameters for a constant value of $H$ and $\gamma$ increases as the value of $H / l_{y}$ ratio increases.

In this study, the mode shapes of the plate on elastic foundation are also obtained for all parameters considered. Since presentation of all of these mode shapes would take up excessive space, only the mode shapes corresponding to the six lowest frequency parameters of the plate for $\gamma=1, H=5$ and $l_{y} / l_{x}=2.00$ are presented. These mode shapes are given in Fig. 8. 
The results obtained in this study are not compared with the results of one or two parameter models because the results given in the literature are dependent on soil parameters $k$ and $2 t$, and they are given as an input data depending on the type of the soil only. However, in this study, the soil parameters are not given as an input data. They are calculated as a function of the soil properties and soil depth, geometric and material properties of the plate as well as the type and distribution of the loading. In fact the soil parameters in Modified Vlasov Model are calculated within the program depending on the vertical deformation parameter, $\gamma$. Therefore, the comparison of the results will not be appropriate.

\section{Conclusions}

The Modified Vlasov Model and Mindlin plate theory have been effectively applied to the free vibration analysis of plates on elastic foundations. In this study, the soil parameters $k$ and $2 t$, are not given as input data, but they are calculated depending on the vertical deformation parameter, $\gamma$, within the subsoil. In addition, the following conclusions can be drawn from the results obtained in the study.

- The frequency parameter always increases with increasing $H / l_{y}$ ratio for any values of the subsoil depth $(H)$ and the vertical deformation parameter within the subsoil $(\gamma)$.

- The frequency parameter always decreases as the subsoil depth $(H)$ increases for any values of $l_{y} / l_{x}$ or $H / l_{y}$ ratio.

- The frequency parameter always decreases with increasing $l_{y} / l_{x}$ ratio for any values of the subsoil depth $(H)$ and the vertical deformation parameter with in the subsoil $(\gamma)$.

- In general, the effects of the change in the subsoil depth on the frequency parameters of the plates on elastic foundations are always larger than those of the other parameters considered in the study.

\section{References}

[1] A.P.S. Selvaduari, Elastic Analysis of Soil-Foundation Interaction, Elsevier Scientific Publishing Company, Amsterdam, 1979.

[2] M.H. Omurtag, A. Özütök, A.Y. Aköz and Y. Özçelikörs, Free vibration analysis of Kirchhoff plates resting on elastic foundation by mixed finite element formulation based on Gateaux differential, International Journal for Numerical Methods in Engineering 40 (1997), 295-317.

[3] M.H. Omurtag and F. Kadığlu, Free vibration analysis of orthotropic plates resting on Pasternak foundation by mixed finite element formulation, Computers and Structures 67 (1998), 253-265.

[4] Y. Ayvaz, A. Daloğlu and A. Doğangün, Application of a modified Vlasov model to earthquake analysis of plates resting on elastic foundations, Journal of Sound and Vibration 212(3) (1998), 499-509.

[5] A. Daloğlu, A. Doğangün and Y. Ayvaz, Dynamic analysis of foundation plates using a consistent Vlasov Model, Journal of Sound and Vibration 224(5) (1999), 941-951.

[6] H. Matsunaga, Vibration and stability of thick plates on elastic foundations, Journal of Engineering Mechanics 126(1) (2000), 27-34.

[7] H.S. Shen, J. Yang and L. Zhang, Free and forced vibration of Reissner-Mindlin plates with free edges resting on elastic foundations, Journal of Sound and Vibrations 244(2) (2001), 299-320.

[8] Y. Xiang, Vibration of rectangular Mindlin plates resting on non-homogenous elastic foundations, International Journal of Mechanical Sciences 45 (2003), 1229-1244.

[9] P. Malekzadeh and G. Karami, Vibration of non-uniform thick plates on elastic foundation by differential quadrature method, Engineering Structures 26 (2004), 1473-1482.

[10] A.Y.T. Leung and B. Zhu, Transverse vibration of Mindlin plates on two parameter foundations by analytical trapezoidal p-elements, Journal of Engineering Mechanics 131(11) (2005), 1140-1145.

[11] D. Zhou, S.H. Lo, F.T.K. Au and Y.K. Cheung, Three-dimensional free vibration of thick circular plates on Pasternak foundation, Journal of Sound and Vibration 292 (2006), 726-741.

[12] C.V.G. Vallabhan and A.T. Daloglu, Consistent FEM-Vlasov model for plates on layered soil, Journal of Structural Engineering, ASCE 125(1) (1999), 108-113.

[13] W. Weaver and P.R. Jonhston, Finite Elements for Structural Analysis, Prentice-Hall, New Jersey, 1984.

[14] K. Ozgan, Finite element analysis of thick plates resting on elastic foundation using modified Vlasov model and determination of the effective depth of the soil stratum, Ph.D. Thesis, Karadeniz Technical University, Turkey, 2007 (in Turkish). 

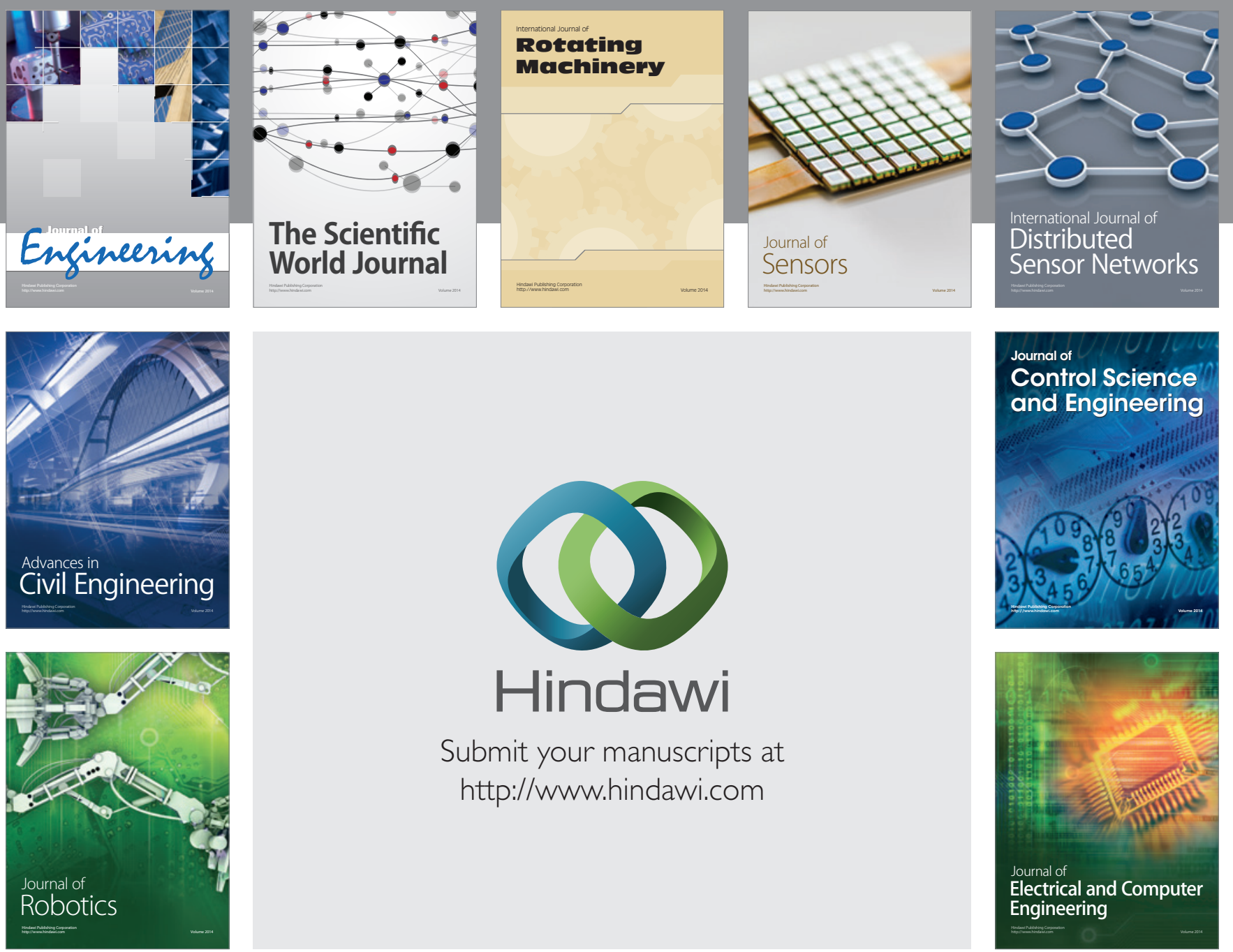

Submit your manuscripts at

http://www.hindawi.com
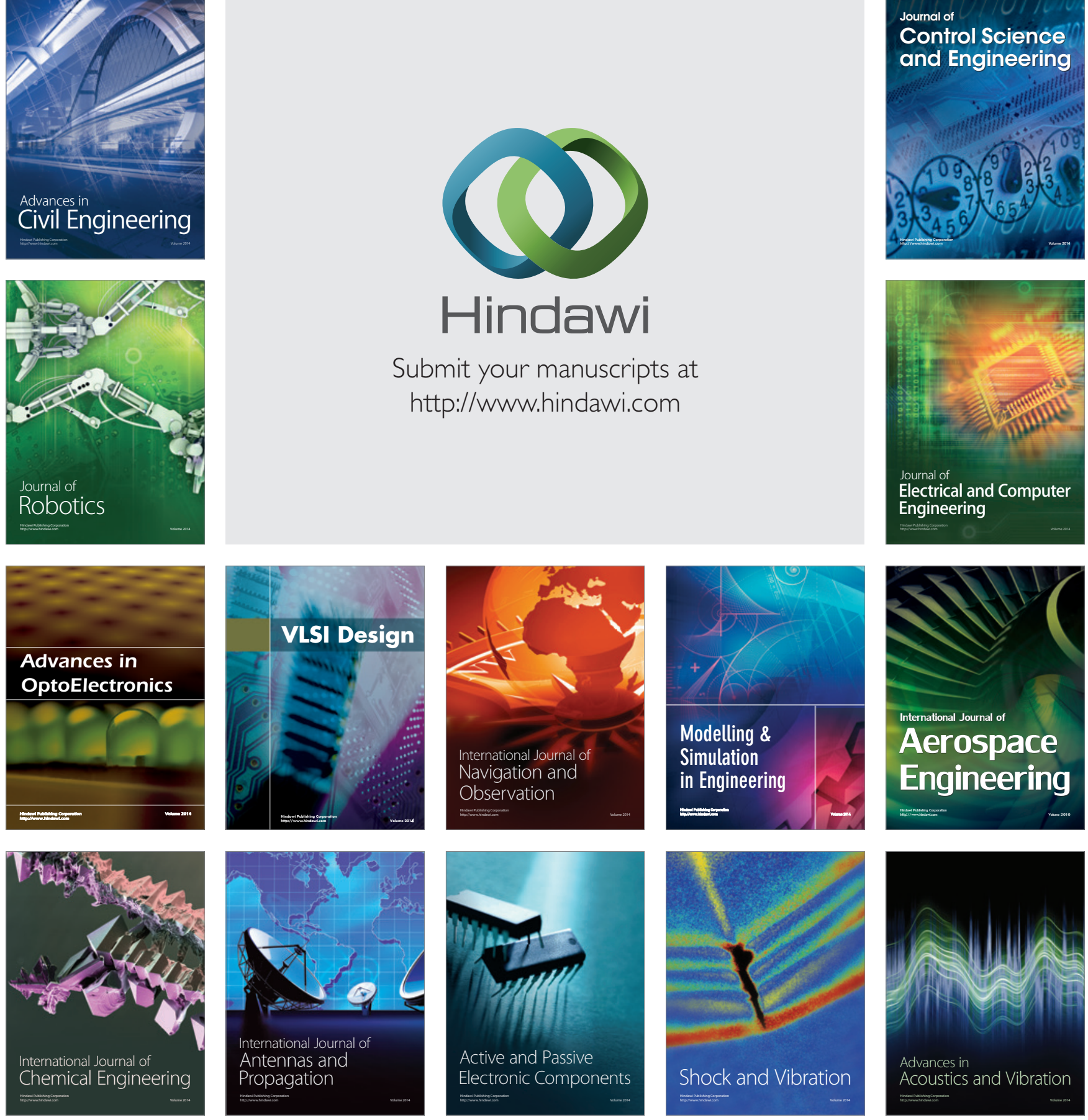